\title{
Evaluation of anti-microbial effect of different concentrations of calendula extract (calendula officinalis) on periodontal pathogens
}

\author{
Dr. Divyanshu Jamwal (MDS) ${ }^{*}$, Dr. Ketaki Kanade(MDS)* \\ *MDS \\ DOI: $10.29322 /$ IJSRP.10.06.2020.p10276 \\ http://dx.doi.org/10.29322/IJSRP.10.06.2020.p10276
}

\begin{abstract}
Calendula Officinalis which belongs to the family Asteraceae, and most commonly known as 'pot marigold', is used medicinally in different forms like infusion, tinctures, liquid extracts, creams or ointment. Aim: The aim of present was to evaluate the anti-microbial effect of different concentrations of calendula extract (Calendula officinalis) on periodontal pathogens. Material and Methods: The study was conducted on twenty five patients having chronic gingivitis and twenty five patients having chronic periodontitis above the age of 18 years were enrolled in the study with the written informed consent. Patients which are under antibiotic coverage, or have any other history of systemic diseases or conditions, including pregnancy, were excluded from the study. The subjects were assessed for chronic periodontitis by recording periodontal pocket probing depth and chronic gingivitis by recording the gingival index. The subjects were assigned into two groups Group A- 25 patients with chronic gingivitis and Group B- 25 patients with chronic periodontitis. Supragingival and sub-gingival plaque samples was collected using a gracey curette. The plaque sample was then tested in laboratory for assessment of total microbial count against different concentrations (5\%, 20\% and 100\%) of calendula officinalis extract. Result: The result showed stastically reduction in total microbial count after the use of 5\%, 20\% and $100 \%$ concentrations of calendula officinalis in both the Group A and B. Conclusion: From the outcome of study it can be concluded that different concentrations of Calendula officinalis mouthwash are effective in reduction of total microbial count in patients with gingivitis and periodontitis.
\end{abstract}

Index Terms- Calendula officinalis, mouthwashes, anti-plaque agents, anti-inflammatory, anti-gingivitis.

\section{INTRODUCTION}

$\mathrm{G}$ ingival and periodontal disease are affecting majority of $\mathbf{J}_{\text {population across the world. Several types of accretions }}$ occurring on the teeth are related to periodontal disease in one way or other. Amongst these dental plaque has posed a real challenge. The research of Harold Loe (1965) considered plaque as a paramount factor in initiation and progression of gingival and periodontal disease ${ }^{(1)}$. The council of Therapeutics of American Dental association (1985) has been described as "highly variable structural entity resulting from colonization and growth of microorganisms on the surface of teeth and oral soft tissues and consist of number of microbial species and strains embedded ing an extracellular matrix"(2). Since bacterial plaque has been the principal causative factor in gingival and periodontal diseases, the most rational methodology towards prevention of periodontal diseases would be regular, effective removal of plaque $^{(2,3)}$. Plaque control measures include mechanical and chemical methods ${ }^{(4)}$. Mechanical method include brushing, use of interdental cleansing aids such as flossing and oral prophylaxis carried out by professionals. These methods have to be proven to be time consuming and their effectiveness entirely depend on the skills and technique used to carrying out these procedures. It is often considered difficult for mainitaning plaque control, particularly at interproximal sites, which necessitates the use of chemicals for control of plaque as an adjunct to mechanical procedures which are used for plaque control. Calendula officinalis which belongs to the family Asteraceae also known as 'pot marigold' which produces yellow or orange flowers and are is medicinally either in form of liquid extract, cream, infusion, tincture or ointment. The plant contains polysaccharides, flavonoids, triterpene alcohol, phenol acids, tannins, glycosides, sterols and carotenoids. ${ }^{(5)}$ Calendula officinalis is known to have anti-bacterial ${ }^{(6,7)}$, anti-fungal activity. ${ }^{(8)}$ It also exhibits wound healing, re-epithelization, ${ }^{(9)}$ anti-inflammatory, ${ }^{(10,11)}$ antioxidant, ${ }^{(12)}$ immunomodulatory ${ }^{(13,14)}$ and anti-mutagenic properties. ${ }^{(15,16)}$. Many mouthwashes with medicinal plant extracts are currently used for maintenance of oral hygiene although there is little information in literature about antibacterial properties of these plant extract against periodontal pathogens. Therefore, this in vitro study was done to evaluate the anti-microbial effect of different concentrations of Calendula extracts (Calendula officinalis) on periodontal pathogens.

\section{SU BJECTS AND METHOD}

A total of fifty subjects were selected from Out Patient Department of Periodontology, Bharati Vidyapeeth Deemed to be University Dental College and Hospital, Pune. The inclusion criteria was systematically healthy subjects, 
subjects with age above 18 years, subjects of both the sex, subjects who have not undergone similar investigations in past 4 weeks and the subjects willing to give informed consent. The exclusion criteria included subjects with systemic disease, pregnant or lactating mothers, subjects with antibiotic therapy in past 30 days and subjects with deleterious habits like smoking and tobacco chewing. The 50 subjects selected were then divided into two groups: Group A consisted of 25 subjects with chronic gingivitis and Group B consisted $\mathrm{s}$ Subjects with chronic periodontitis and the informed written consent was obtained from each subject. The subjects were examined on dental chair under standard conditions of light using diagnostic instruments (mouth mirror, probe, explorer and tweezer). The relevant data and clinical findings were recorded on special performa designed for this study so as to have systematic and methodical recording for all the information and observations. The periodontal probing depth was recorded and gingival index ( Loe and Sillness, 1963) was taken. After recording all the preoperative clinical parameters the Supra-gingival plaque sample was obtained from Group A subjects and sub-gingival plaque samples was obtained from Group B subjects using a gracey curette. The plaque sample was immediately transported to thiogylcolate medium and it was spreaded on nutrient agar plate with the help of spreader and then different dilutions of calendula officinalis tincture (5\%, 20\% and 100\%) was added on the nutrient agar plate then it was incubated at $37^{\circ} \mathrm{C}$ for $48 \mathrm{hrs}$. The microbial count which was obtained was checked against different concentrations of Calendula Officinalis. The results obtained were arranged in a master chart and subjected to statistical analysis.

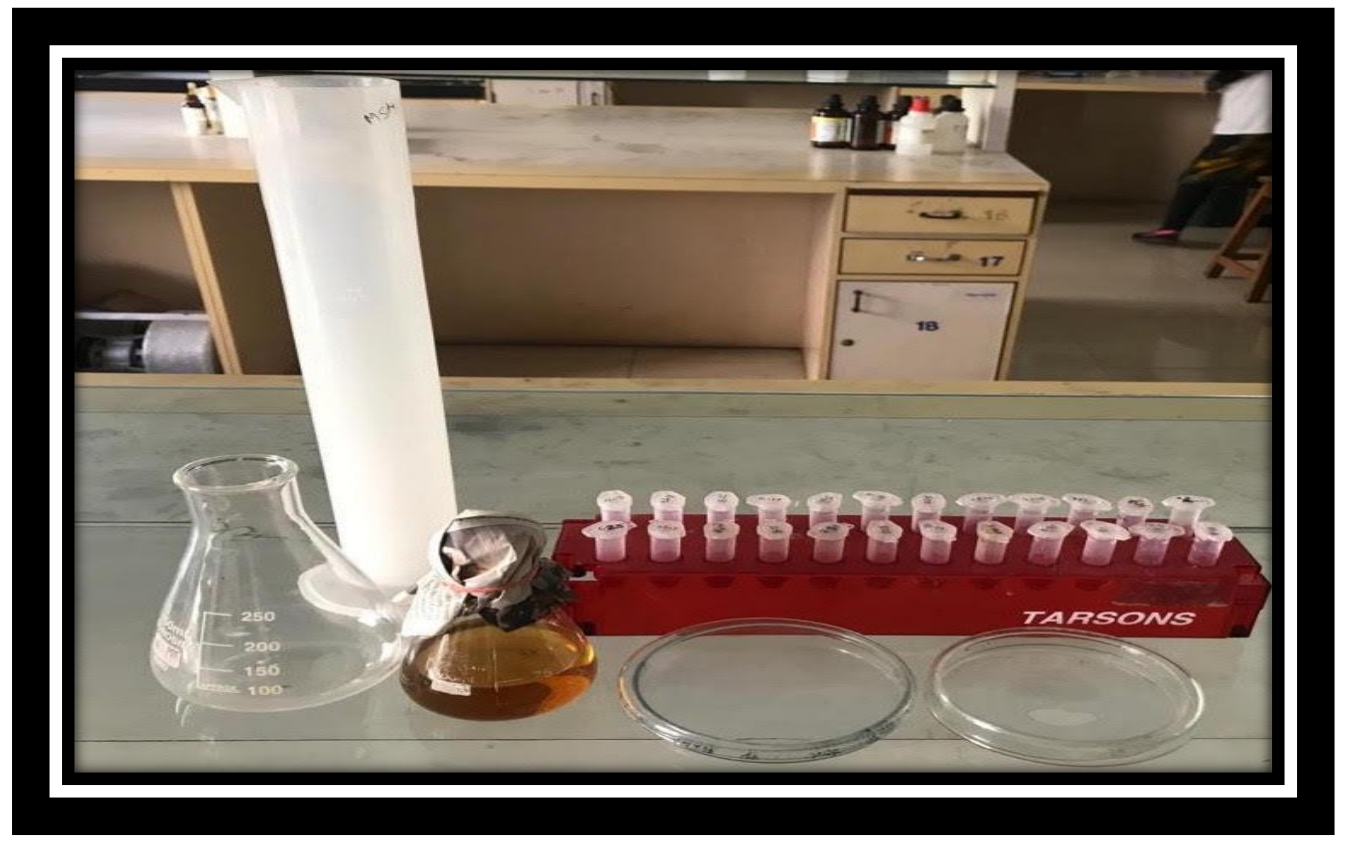

Figure 1: Armamentarium used for microbiological study

Preparation of calendula officinalis tincture

Calendula officinalis tincture was prepared from the plant calendula officinalis. For preparation, the finely chopped fresh flowers and leaves were firstly dried in sunlight before the preparation of tincture. For preparation placed about 1/41 cup of calendula petals and leaves in a jar and cover them with twice as much $80 \%$ alcohol . After adding alcohol seal it with lid and leave the container out in sunlight for 2-8 weeks. After 2-8 weeks strain and transfer the solution to an amber tincture bottle. Mother tincture of calendula officinalis was made which was used by making different dilutions $(5 \%, 20 \%$ and $100 \%)$ with water.

\section{STATISTICAL ANALYSIS}

1.Intergroup comparison of antimicrobial efficacy in terms of varying concentrations $(5 \%, 20 \%$ and 100\%) of calendula officinalis extract against periodontal pathogens in gingivitis cases (Group A) and periodontitis cases (Group B) was carried out using ANOVA test.

2.Intragroup comparison of antimicrobial efficacy in terms of varying concentrations $(5 \%, 20 \%$ and $100 \%)$ of calendula officinalis extract against periodontal pathogens in gingivitis cases (Group A) and periodontitis cases (Group B) was carried out using unpaired t-test.

3. Descriptive studies include mean and standarad deviation which were calculated for gingivitis group (Group A) and periodontitis (Group B).

\section{RESULTS}

The results thus obtained were arranged in master charts and statistical analysis was carried out. Inter group statistical analysis was performed using ANOVA test. The comparison 
of anti-microbial efficacy of varying concentrations $(5 \%$, $20 \%$ and $100 \%$ ) of calendula officinalis extract against periodontal pathogens in gingivitis cases (Group A) was performed using ANOVA test. The mean values for 5\% concentration of calendula officinalis was 91640.00 with a standard deviation of 14182.97 , for $20 \%$ concentration of calendula officinalis was 69440.00 with standard deviation of 19004.561 and for $100 \%$ concentration of calendula officinalis was 41600.00 with standard deviation of 17209.494. Using Tukey's post hoc test, $P$ value was found to be $<0.001$ indicating that there was a statistically highly noticeable reduction in total microbial count at $100 \%$ concentration as compared to $5 \%$ and $20 \%$ concentration in gingivitis cases(Table1, Graph1).

Table 1: Comparison of antimicrobial efficacy in terms of varying concentrations (5\%, 20\% and $100 \%)$ of calendula officinalis extract against periodontal pathogens in gingivitis cases (Group A) using ANOVA test

\begin{tabular}{|l|l|l|l|l|l|}
\hline $\begin{array}{l}\text { Calendula } \\
\text { officinalis }\end{array}$ & N & Mean & Std. Deviation & F value & P value \\
\hline $5 \%$ & 25 & 91640.00 & 14182.971 & & \\
\hline $20 \%$ & 25 & 69440.00 & 19004.561 & $50.001 * *$ \\
\hline $100 \%$ & 25 & 41600.00 & 17209.494 & & \\
\hline Total & 75 & 67560.00 & 26517.837 & & \\
\hline
\end{tabular}

$(\mathrm{p}<0.05-$ Significant $*$, $<0.001-$ Highly significant**)

(Tukey's post hoc analysis)

\begin{tabular}{|l|l|l|l|}
\hline & $5 \%$ & $20 \%$ & $100 \%$ \\
\hline $5 \%$ & - & $<0.001 * *$ & $<0.001 * *$ \\
\hline $20 \%$ & $<0.001 * *$ & - & $<0.001 * *$ \\
\hline $100 \%$ & $<0.001 * *$ & $<0.001 * *$ & - \\
\hline
\end{tabular}


Graph 1: Comparison of antimicrobial efficacy of varying concentrations $(5 \%, 20 \%$ and $100 \%)$ of calendula officinalis extract against periodontal pathogens in gingivitis cases (Group A) cases using ANOVA test

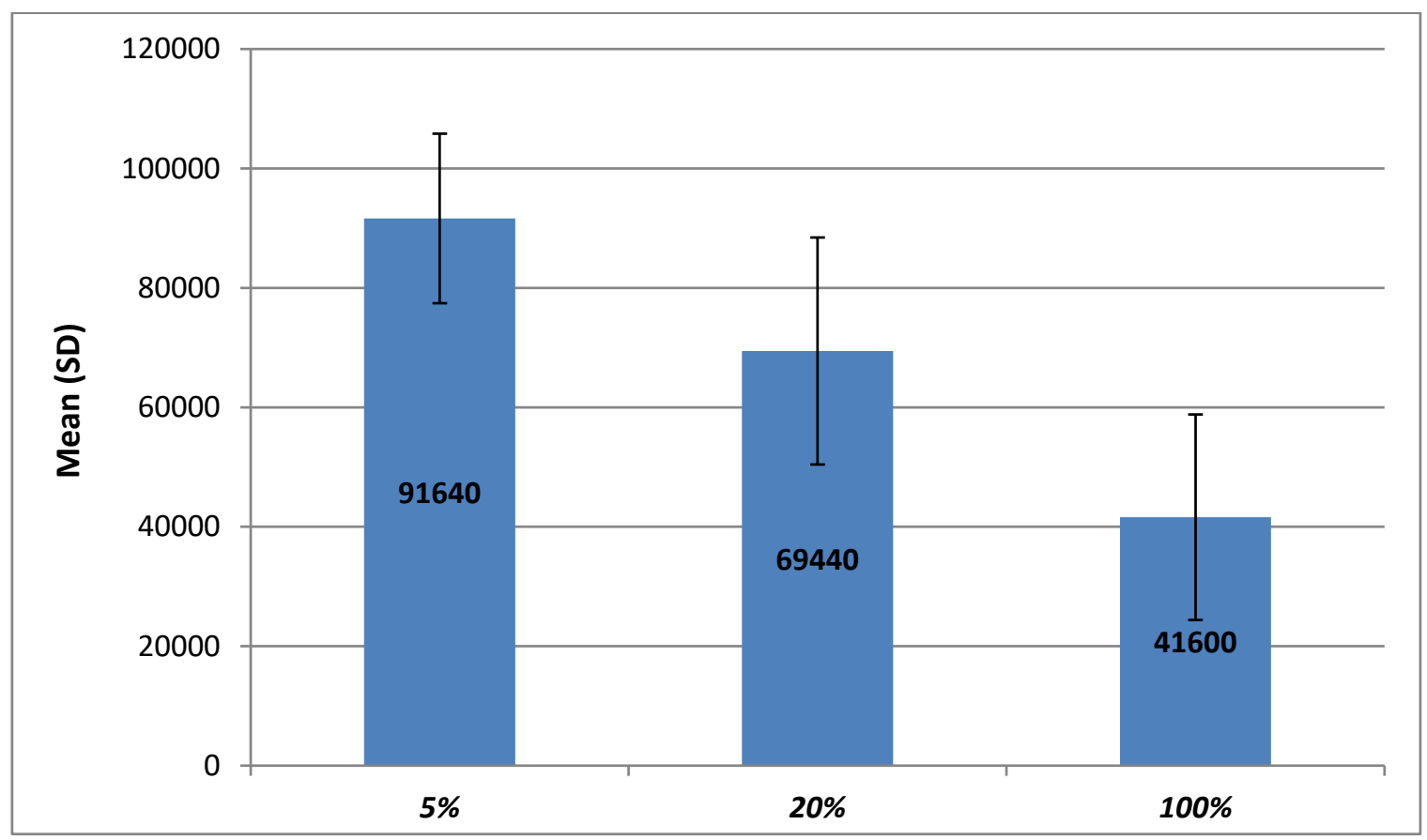

The comparison of antimicrobial efficacy of varying concentrations $(5 \%, 20 \%$ and $100 \%)$ of calendula officinalis extract \& controls against periodontal pathogens in gingivitis cases (Group A) using ANOVA test was performed. The mean values for 5\%, $20 \%$ and $100 \%$ was same as above with control group added in it and for control group it was
89880.00 with standard deviation of 42890.675 . Using Tukey's post hoc test, $\mathrm{P}$ value was found to be $<0.001$ indicating that there was a statistically highly noticeable reduction in total microbial count at $100 \%$ concentration as compared to control group, $5 \%$ and $20 \%$ concentration in gingivitis cases(Table2, Graph2).

Table 2: Comparison of antimicrobial efficacy of varying concentrations $(5 \%, 20 \%$ and $100 \%)$ of calendula officinalis extract \& controls against periodontal pathogens in gingivitis cases (Group A) using ANOVA test

\begin{tabular}{|l|l|l|l|l|l|}
\hline $\begin{array}{l}\text { Calendula } \\
\text { officinalis }\end{array}$ & N & Mean & Std. Deviation & F value & P value \\
\hline $5 \%$ & 25 & 91640.00 & 14182.971 & & \\
\hline $20 \%$ & 25 & 69440.00 & 19004.561 & 20.149 & \\
\cline { 1 - 4 } & 25 & 41600.00 & 17209.494 & & \\
\cline { 1 - 4 } Controls & 25 & 89880.00 & 42890.675 & & \\
\hline
\end{tabular}

$(\mathrm{p}<0.05-$ Significant*, $\mathrm{p}<0.001-$ Highly significant**) 
(Tukey's post hoc analysis)

\begin{tabular}{|l|l|l|l|l|}
\hline & $5 \%$ & $20 \%$ & $100 \%$ & Controls \\
\hline $5 \%$ & - & $0.017^{*}$ & $<0.001^{* *}$ & 0.995 \\
\hline $20 \%$ & $0.017^{*}$ & - & $<0.001^{* *}$ & $0.032^{*}$ \\
\hline Controls & 0.995 & $<0.001^{* *}$ & - & $<0.001^{* *}$ \\
\hline
\end{tabular}

Graph 2: Comparison of antimicrobial efficacy of varying concentrations $(5 \%, 20 \%$ and $100 \%)$ of calendula officinalis extract \& controls against periodontal pathogens in gingivitis cases (Group A) using ANOVA test

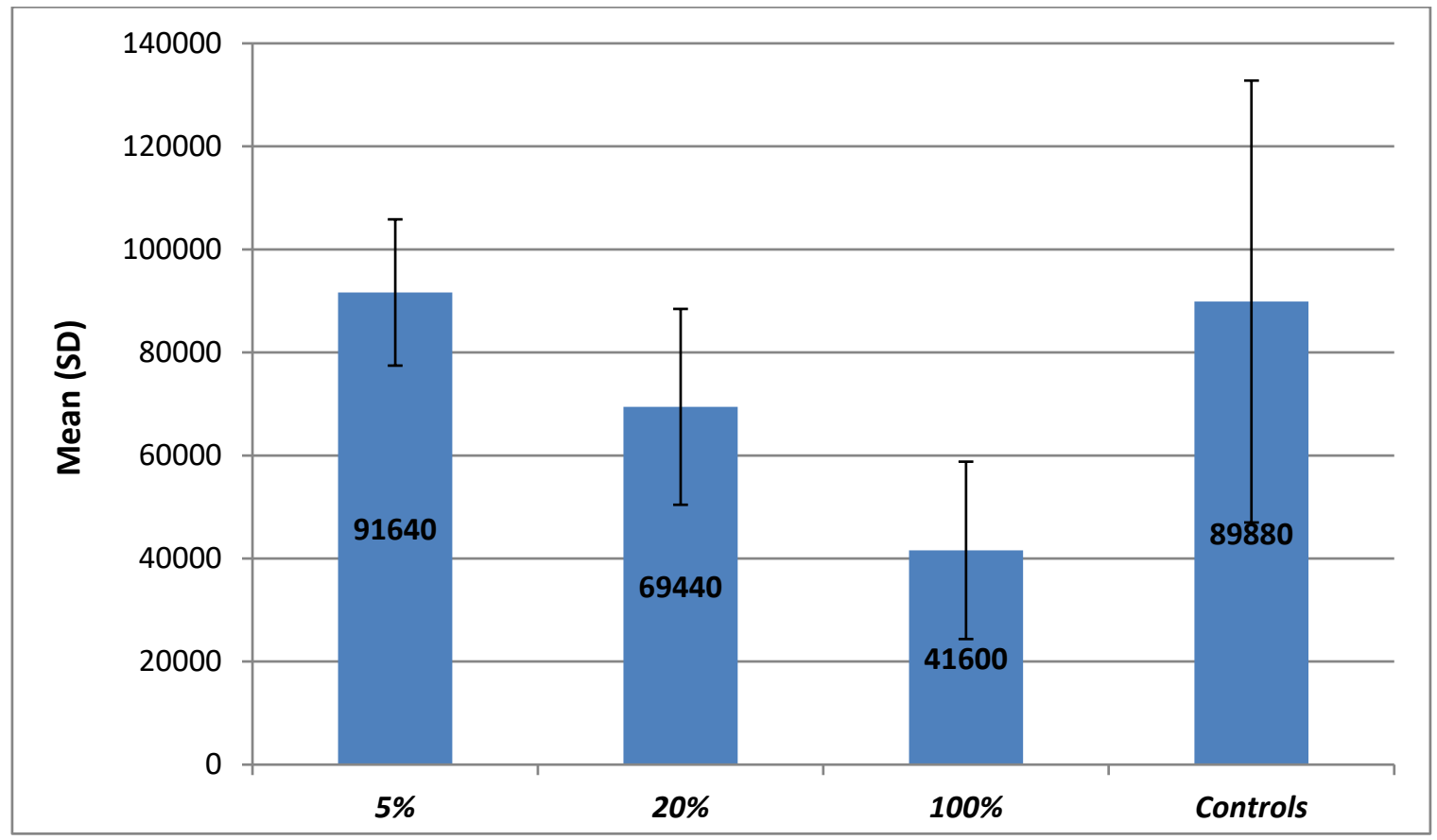

Similarly, the comparison of antimicrobial efficacy of varying concentrations $(5 \%, 20 \%$ and $100 \%)$ of calendula officinalis extract against periodontal pathogens in periodontitis cases (Group B) using ANOVA test was performed. The mean values for 5\% concentration of calendula officinalis was 86000.00 with standard deviation of 14221.463 , for $20 \%$ concentration of calendula officinalis was
68240.00 with standard deviation of 14740.194 and for $100 \%$ concentration of calendula officinalis was 39600.00 with standard deviation of 12599.603. Using Tukey's post hoc test, $\mathrm{P}$ value was found to be $<0.001$ indicating that there was a statistically highly significant in total microbial count at $100 \%$ concentration as compared to $5 \%$ and $20 \%$ concentration in periodontitis cases(Table3, Graph3). 
Table 3: Comparison of antimicrobial efficacy of varying concentrations $(5 \%, 20 \%$ and $100 \%)$ of calendula officinalis extract against periodontal pathogens in periodontitis cases (Group B) using ANOVA test

\begin{tabular}{|l|l|l|l|l|l|}
\hline $\begin{array}{l}\text { Calendula } \\
\text { officinalis }\end{array}$ & $N$ & Mean & Std. Deviation & F value & P value \\
\hline $5 \%$ & 25 & 86000.00 & 14221.463 & & \\
\hline $20 \%$ & 25 & 68240.00 & 14740.194 & & \\
\cline { 1 - 5 } & 25 & 39600.00 & 12599.603 & & \\
\cline { 1 - 4 } & 75 & 64613.33 & 23619.674 & & \\
\hline
\end{tabular}

$\left(\mathrm{p}<0.05\right.$ - Significant* ${ }^{*} \mathrm{p}<0.001-$ Highly significant**

(Tukey's post hoc analysis)

\begin{tabular}{|l|l|l|l|}
\hline & $5 \%$ & $20 \%$ & $100 \%$ \\
\hline $5 \%$ & - & $<0.001 * *$ & $<0.001 * *$ \\
\hline $20 \%$ & $<0.001 * *$ & - & $<0.001 * *$ \\
\hline $100 \%$ & $<0.001 * *$ & $<0.001 * *$ & \\
\hline & & & \\
\hline
\end{tabular}


Graph 3: Comparison of antimicrobial efficacy of varying concentrations $(5 \%, 20 \%$ and $100 \%)$ of calendula officinalis extract against periodontal pathogens in periodontitis cases (Group B) using ANOVA test

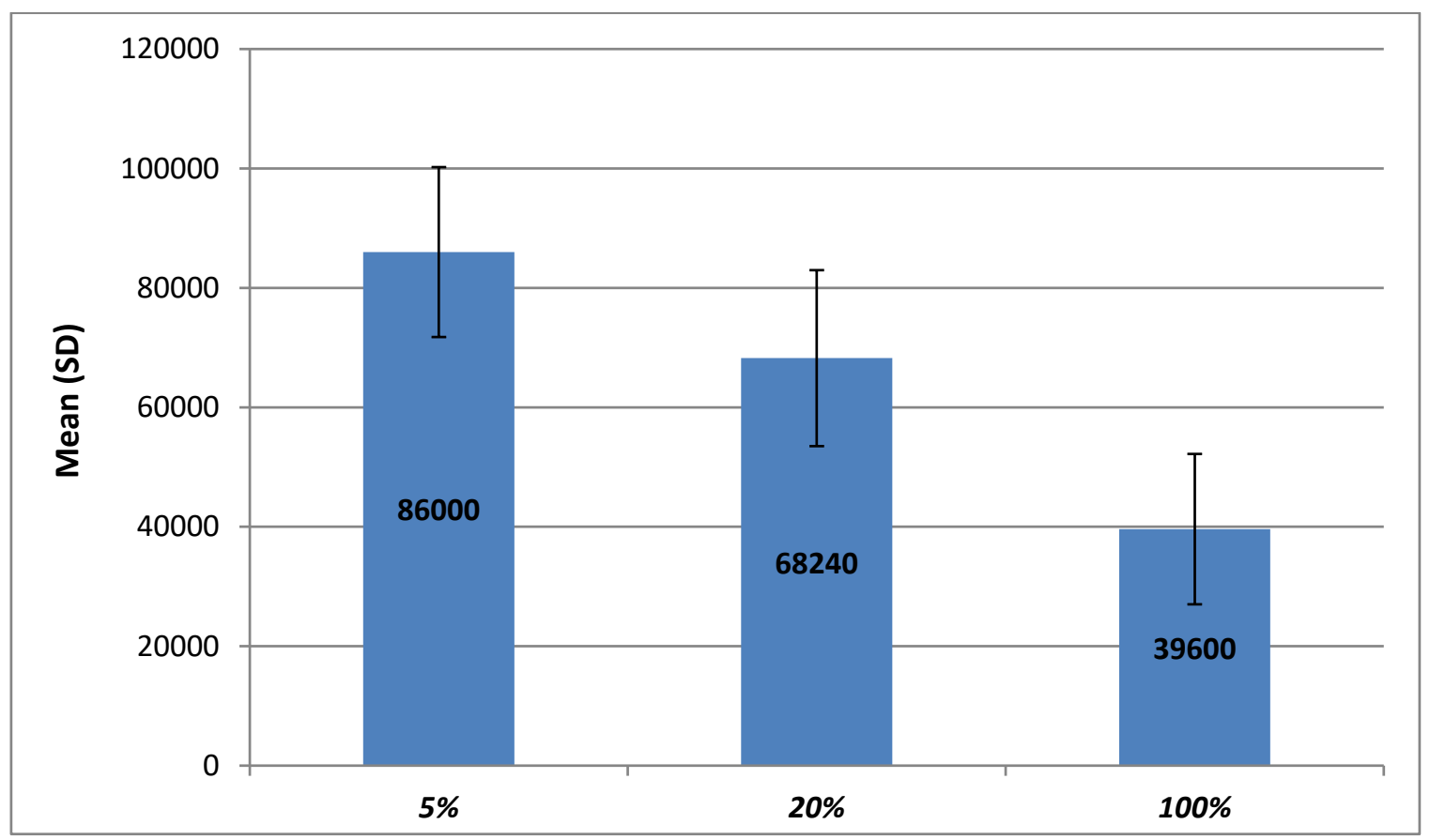

The Comparison of antimicrobial efficacy of varying concentrations $(5 \%, 20 \%$ and $100 \%)$ of calendula officinalis extract \& controls against periodontal pathogens in periodontitis cases (Group B) using ANOVA test. The mean values for $5 \%, 20 \%$ and $100 \%$ was same as above it control group added in it for control group it was 92320.00 with standard deviation of 32042.576. Using Tukey's post hoc test, $\mathrm{P}$ value was found to be $<0.001$ indicating that there was a statistically highly significant in total microbial count at $100 \%$ concentration as compared to control group, 5\% and 20\% concentration in periodontitis cases(Table4, Graph4).

Table 4: Comparison of antimicrobial efficacy of varying concentrations $(5 \%, 20 \%$ and $100 \%)$ of calendula officinalis extract \& controls against periodontal pathogens in periodontitis cases (Group B) using ANOVA test

\begin{tabular}{|c|c|c|c|c|c|}
\hline $\begin{array}{l}\text { Calendula } \\
\text { officinalis }\end{array}$ & $N$ & Mean & Std. Deviation & $F$ value & $P$ value \\
\hline $5 \%$ & 25 & 86000.00 & 14221.463 & \multirow{5}{*}{34.724} & \multirow{5}{*}{$<0.001 * *$} \\
\hline $20 \%$ & 25 & 68240.00 & 14740.194 & & \\
\hline $100 \%$ & 25 & 39600.00 & 12599.603 & & \\
\hline Controls & 25 & 92320.00 & 32042.576 & & \\
\hline Total & 100 & 71540.00 & 28483.353 & & \\
\hline
\end{tabular}

$(\mathrm{p}<0.05$ - Significant*, $\mathrm{p}<0.001$ - Highly significant**)

Tukey's post hoc analysis) 


\begin{tabular}{|l|l|l|l|l|}
\hline & $5 \%$ & $20 \%$ & $100 \%$ & Controls \\
\hline $5 \%$ & - & $0.012^{*}$ & $<0.001^{* *}$ & 0.681 \\
\hline $20 \%$ & $0.012^{*}$ & - & $<0.001^{* *}$ & $<0.001^{* *}$ \\
\hline $100 \%$ & $<0.001^{* *}$ & $<0.001^{* *}$ & - & $<0.001^{* *}$ \\
\hline Controls & 0.681 & $<0.001^{* *}$ & $<0.001^{* *}$ & - \\
\hline
\end{tabular}

Graph 4: Comparison of antimicrobial efficacy of varying concentrations $(5 \%, 20 \%$ and $100 \%)$ of calendula officinalis extract \& controls against periodontal pathogens in periodontitis cases (Group B) cases using ANOVA test

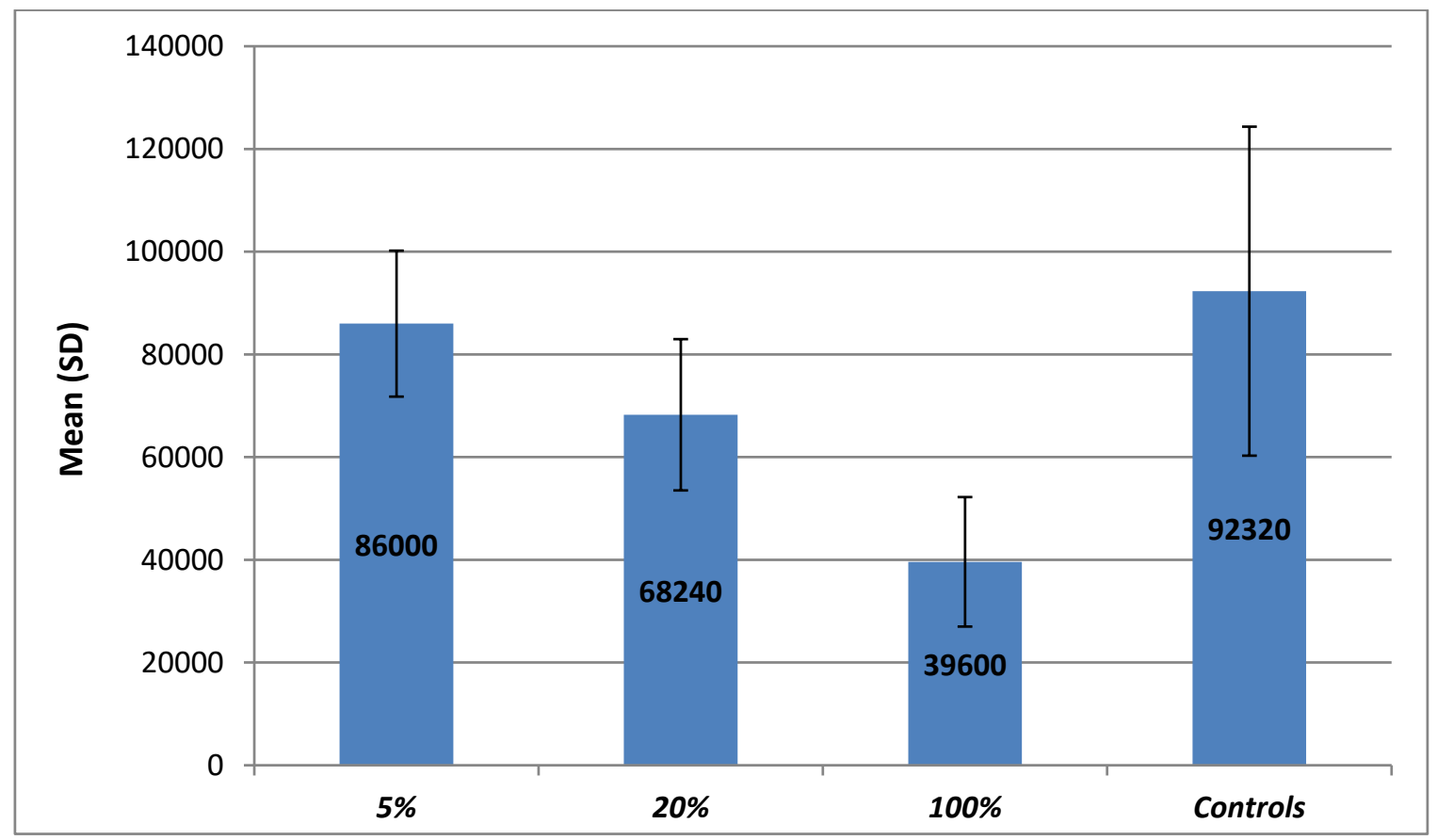

An intra group comparison of gingivitis (Group A) and periodontitis ( Group B) was carried out for evaluating the efficacy of varying (5\%,20\% and 100\%) concentrations of calendula officinalis extract and controls against periodontal pagthogens using unpaired t-test. The mean values for 5\% concentration of calendula officinalis was $91640.00 \pm 14182.971$ for gingivitis (Group A) and 86000.00 \pm 14221.463 for periodontitis (Group B). On the basis of unpaired t-test there was no statistical difference between the two groups. The mean value for $20 \%$ concentration of calendula officinalis was $69440.00 \pm 19004.561$ for gingivitis (Group A) and $68240.00 \pm 14740.194$ for periodontitis (Group B). On the basis of unpaired t-test there was no statistical difference between the two group. The mean value for $100 \%$ concentration of calendula officinalis was $41600.00 \pm 17209.494$ for gingivitis (Group A) and $39600.00 \quad \pm 12599.603$ for 
periodontitis (Group B). On the basis of unpaired t-test there was no statistical difference between the two group. The mean value for control group was $89880.00 \pm 42890.675$ for gingivitis (Group A) and $92320.00 \pm 32042.576$ for periodontitis (Group B). On the basis of unpaired t-test there was no stastistical difference between the two groups(Table5, Graph5).

Table 5: Comparison of antimicrobial efficacy of varying concentrations $(5 \%, 20 \%$ and $100 \%)$ of calendula officinalis extract \& controls against periodontal pathogens in gingivitis (Group A) \& periodontitis (Group B) cases using unpaired test

\begin{tabular}{|c|c|c|c|c|c|c|}
\hline & Group & $N$ & Mean & Std. Deviation & $t$ value & $P$ value \\
\hline \multirow{2}{*}{$5 \%$} & Gingivitis & 25 & 91640.00 & 14182.971 & \multirow{2}{*}{1.404} & \multirow{2}{*}{0.167} \\
\hline & Periodontitis & 25 & 86000.00 & 14221.463 & & \\
\hline \multirow{2}{*}{$20 \%$} & Gingivitis & 25 & 69440.00 & 19004.561 & \multirow{2}{*}{0.249} & \multirow{2}{*}{0.804} \\
\hline & Periodontitis & 25 & 68240.00 & 14740.194 & & \\
\hline \multirow{2}{*}{$100 \%$} & Gingivitis & 25 & 41600.00 & 17209.494 & \multirow{2}{*}{0.469} & \multirow{2}{*}{0.641} \\
\hline & Periodontitis & 25 & 39600.00 & 12599.603 & & \\
\hline \multirow{2}{*}{ Control } & Gingivitis & 25 & 89880.00 & 42890.675 & \multirow{2}{*}{0.228} & \multirow{2}{*}{0.821} \\
\hline & Periodontitis & 25 & 92320.00 & 32042.576 & & \\
\hline
\end{tabular}


Graph 5: Comparison of antimicrobial efficacy of varying concentrations $(5 \%, 20 \%$ and $100 \%)$ of calendula officinalis extract \& controls against periodontal pathogens in gingivitis (Group A) \& periodontitis (Group B) cases using unpaired $\mathbf{t}$ test
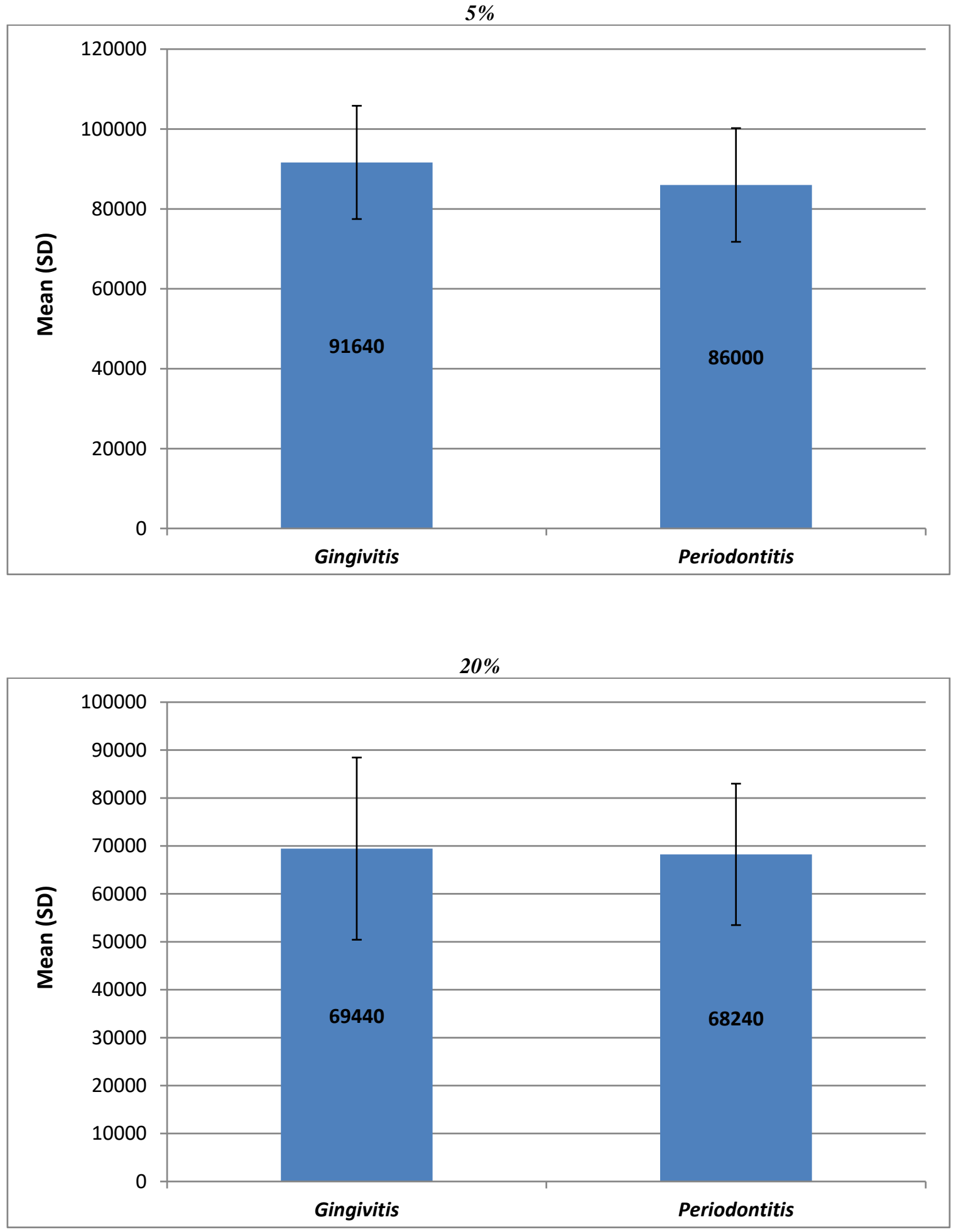

$100 \%$ 

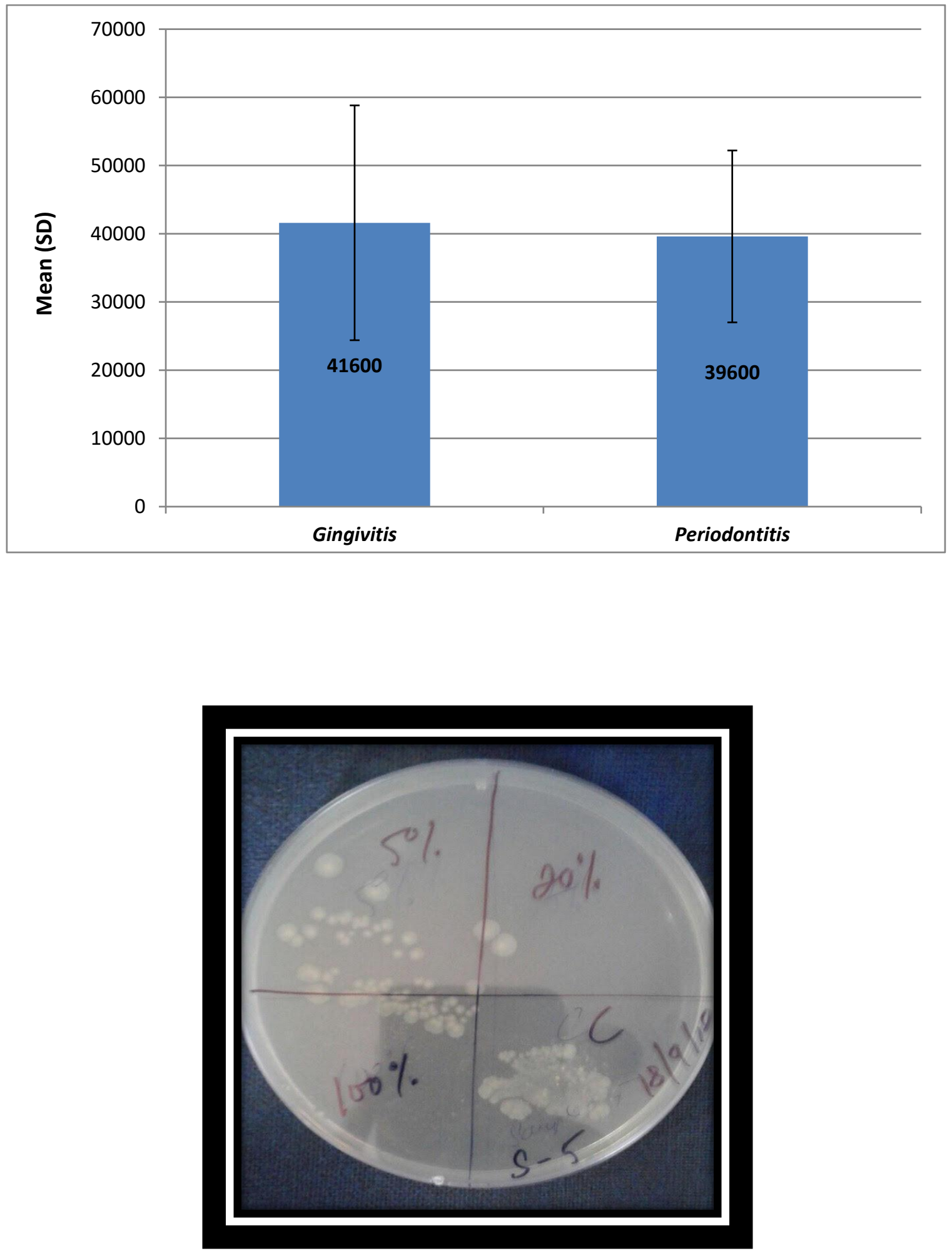

Figure 2: Nutrient agar plate showing total microbial count in Gingivitis patients (Group A) using different concentrations of calendula officinalis $(5 \%, 20 \%, 100 \%$ and control group). 


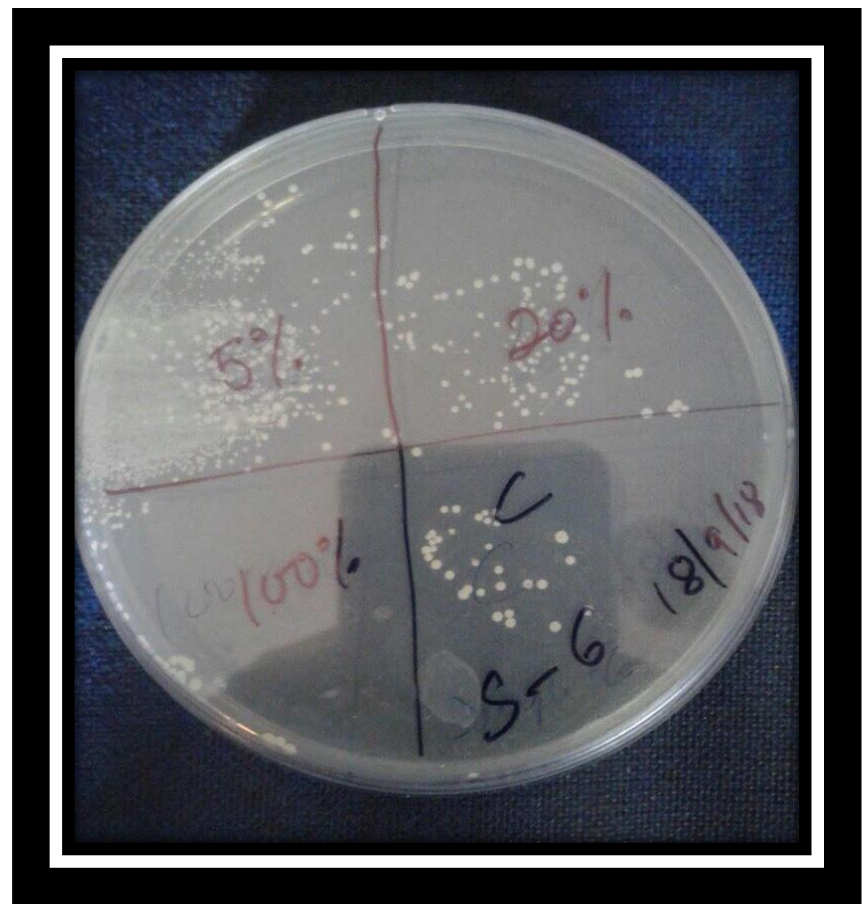

Figure 3: Nutrient agar plate showing total microbial count in Periodontitis patients (Group B) using different concentrations of calendula officinalis $(5 \%, 20 \%, 100 \%$ and control group).

\section{DISCUSSION}

Dental plaque is one of the etiologic factors for gingivitis and periodontitis. Optimal plaque control is essential to prevent or arrest gingival inflammation. Mechanical measures such as tooth brushing, flossing, use of interdental aids are the most commonly used methods to clean the teeth. However, it has been revealed that complete plaque control cannot be achieved by majority of patients. Furthermore, for handicapped or elderly individuals use of mechanical plaque control methods is more challenging due to their compromised dexterity or lack of motivation ${ }^{(17)}$. To overcome these shortcomings, various chemical plaque inhibitors have been tried along with mechanical aids. Chlorohexidine is the most commonly used and extensively studied chemical agent for plaque control. It is considered as the gold standarad amongst anti-plaque agents. Inspite of potent antimicrobial and antiplaque properties of chlorohexidine, its widespread and prolonged use is limited by its local side effects. The adverse effects of chlorohexidine include extrinsic staining of teeth, transient impairment of taste sensation and perturbation ${ }^{(18,19)}$.

Chakraborthy, G. S. (June 2008) ${ }^{(20)}$ the study was conducted to evaluate the antimicrobial activity of different extracts of leaves of Calendula officinalis Linn. The antibacterial and antifungal activity was carried out by employing 24hr cultures of Bacillus subtulis, Staphylococcus aureus, Escherichia coli, Klebsiella pneumonia, Candida albicans and Aspergillus niger ${ }^{20}$. The results reveal that extracts of C.officinalis leaves were significantly effective against both Gram-positive and Gram-negative organism ${ }^{20}$.

Efstratios Efstratiou, Abdullah I. Hussain (2012) ${ }^{(21)}$ conducted a study to assess the antimicrobial activity of $\mathrm{C}$. officinalis extracts against a range of clinical fungal and bacterial pathogens. The antimicrobial activity of methanol and ethanol extracts of calendula officinalis were individually tested against panel of pathogenic microorganisms ${ }^{21}$. The results of the study indicate that the methanol and ethanol extracts have good antimicrobial pactivity. Both the methanol and ethanol extracts showed antifungal activity that is comparable with the standard antibiotic, Fluconazole. Further clinical studies are now required to further examine the antimicrobial principles of $\mathrm{C}$. officinalis for various useful applications.

Khairnar MS et al (2013) $)^{(22)}$ conducted a study for evaluation of Calendula officinalis as an anti-plaque and anti-gingivitis agent ${ }^{22}$. A study was carried out with a test group using the calendula mouthwash and a placebo control group $^{22}$. In the study two hundred and forty patients were randomly assigned into two group (A) Test group $n=120$ and (B) Control group $n=120^{22}$. The test group were advised to dilute $2 \mathrm{ml}$ of calendula tincture with $6 \mathrm{ml}$ of water ${ }^{22}$. This diluted (1:3) formulation was prescribed for mouth rinsing twice daily for 6 months $^{22}$. The control group patients were given distilled water as mouthwash (placebo) and were advised to rinse their mouth with $8 \mathrm{ml}$ of it twice daily for 6 months $^{22}$. All patients were recalled to clinics at third month (second visit) and at the sixth month (third visit) ${ }^{22}$. The clinical parameters included were Gingival index (GI), Sulcus bleeding index (SBI), Turesky-Gilmore modification of the Quigley-Hein plaque index (PI), and Oral hygiene indexsimplified (OHI-S) were recorded at baseline, third month and sixth month ${ }^{22}$. The results shows significant difference in the mean value of PI, GI, SBI scores from the baseline to third month , from the third month to sixth month, and from baseline to sixth month in calendula test group patients ${ }^{22}$. There was significant reduction in 0HI-S scores from third month to sixth month is truly attributed to thorough scaling 
done at third month ${ }^{22}$. They concluded that there is large reduction in dental plaque and gingivitis using Calendula mouthwash. The result indicated that mouthrinsing with 1:3 dilution of $\mathrm{C}$. officinalis prevented plaque formation.

\section{SUMMARY}

The following observations from our study were obtained:

1.There was noticeable significant reduction in total microbial count after using 5\% concentration of calendula officinalis extract as compared to control group in both gingivitis (Group A) and periodontitis (Group B).

2.There was noticeable significant reduction in total microbial count after using $20 \%$ concentration of calendula officinalis extract as compared to $5 \%$ and control group in both gingivitis (Group A) and periodontitis (Group B).

3.There was noticeable significant reduction in total microbial count after using $100 \%$ concentration of calendula officinalis extract as compared to $5 \%, 20 \%$ and control group in both gingivitis (Group A) and periodontitis (Group B).

4.There was noticeable significant more reduction in total microbial count after the use of $5 \%, 20 \%$ and $100 \%$ concentrations of calendula officinalis extract in periodontitis group (Group B) when compared to gingivitis group (Group A)

\section{CONCLUSION}

From the above observation, it can be concluded that $100 \%$ concentration of calendula officinalis extract is more effective against reduction of total microbial count as compared to $5 \%$ and $20 \%$ and it can be used as mouthwash in treating patients with gingivitis and periodontitis. Calendula officinalis mouthwashes are biocompatible and have less side effects as compared to chlorohexidine mouthwash as per the literature. Thus, it can be concluded that different concentrations of Calendula officinalis mouthwash are effective in reduction of total microbial count in patients with gingivitis and periodontitis.

\section{REFERENCES}

[1] Fine H. D: Chemical agents to prevent and regulate plaque development Perio 2000; 1995: 8:87-107.

[2] Lindhe Jan: Textbook of clinical periodontology \& Implant dentistry 4th edi. : 464-486.

[3] Othman Shibly, Susan Rifal \& Joseph J Zambon: Supragingival dental plaque in the etiology of oral disease Perio 2000 Vol 8, Issue 1, Pgs 42-59 June 1995

[4] AAP. Posotion paper: Pathogenesis of periodontal diseases. J. Periodontol 1999; 70: 457.
[5] E.S.C.O.P. (Ed) Monographs (Monographs on Medicinal Uses Of Plants Drug) Exeter (Uk), 1997; V 01-12/06.

[6] Chakraborthy GS. Antimicrobial activity of leaf extract of Calendula officinalis Linn. J Herb Med Toxicol 2008;2:65-6.

[7] Dumenil G, Chemli R, Balasaurd G. Evaluation of antibacterialproperties of Calendula officinalis flowers and mother homeopathic tincture of calendula. Ann Pharm Fran 1980;38:493-9.

[8] Zilda CG, Claudia MR, Sandra RF. Antifungal activity of theessential oil from Calendula officinalis $\mathrm{L}$ growing in Brazil. Braz $\mathrm{J}$ Microbiol 2008;39:61-3.

[9] Rao S G, Udupa A L, Udupa S L. Calendula and hypericum: Twohomeopathic drug promoting wound healing in rats. Fitoteraperia 1991;62:508-10.

[10] Preethi CG, Kuttan G, Kuttan R. Anti-inflammatory activity of flower extract of Calendula officinalis. Linn and its possible mechanism of action. Indian J Exp Biol 2009;47:113-20.

[11] Della Loggia R, Tubaro A, Sosa S, Becker H, Saar S, Isaac O. The role of titerpenoids in topical anti-inflammatory activity of Calendula officinalis flowers. Planta Med 1994;60:516-20.

[12] Preethi KC, Utta GK. Antioxidant potential of an extract of Calendula officinalis in vitro and in vivo. Pharm Biol 2006;44:691-7.

[13] Varljen J, Liptak A, Wagner H. Structural analysis of Rhamnoarabinogalactan and Arabinogalactans with immunostimulating activity from Calendula officinalis. Phytochemistry 1989;28:2379-83.

[14] Wagner H, Proksch A, Riess-Maurer I, Vollmar A, Odenthal S, Stuppner $\mathrm{H}$, et al. Immunostimulating action of polysaccharides (heteroglycans) from higher plants. Arzneimittel for chung 1985;7:1069-75.

[15] Elias R, De Méo M, Vidal-Ollivier E, Laget M, Balansard G, Dumenil G. Antimutgenic activity of some saponins isolated from Calendula officinalis L, arvensis L, hedera helix L. Mutagenesis 1990;5:327-31.

[16] Boucaud-Maitre Y, Algernon O, Raynaud J. Cytotoxic and anti tumoural activity of Calendula officinalis extracts. Pharmazie 1988;43:220-1.

[17] Axelsson P, Lindhe J. Effect of controlled oral hygiene procedure on caries and periodontal disease in adults. Results after 6 years. J Clin Periodontal 1981;8:239-48.

[18] Loe H. Schiott C.R.: The effect of mouth rinse and topical application of chlorohexidine on development of dental plaque and gingivitis; J.Perio Res: 1970: 5:79.

[19] Addy M.: Chlorohexidine compared with other locally delivered antimicrobials: J Clin Periodontol: 1986:13(10):957-64.

[20] Chakraborthy, G. S. Antimicrobial activity of the leaf extracts of calendula officinalis (linn.). Journal of Herbal Medicine and Toxicology 2 (2) 65-66 (2008) ISSN : 0973-4643.

[21] Efstratios Efstratiou, Abdullah I. Hussain. Antimicrobial activity of Calendula officinalis petal extracts against fungi, as well as Gramnegative and Gram-positive clinical pathogens. Complementary Therapies in Clinical Practice 18 (2012) 173-176.

[22] Khairnar MS et al Calendula officinalis as an anti-plaque and anti-gingivitis agent: Journal of Indian Society of Periodontology - Vol 17, Issue 6, Nov-Dec 2013.

\section{AUTHORS}

First Author - Dr. Divyanshu Jamwal, MDS, divyanshujamwal1410@gmail.com

Second Author - Dr. Ketaki Kanade,MDS, kanade.ketaki@gmail.com 